\title{
Comparison of the effects of Penicillin versus Erythromycin in Treatment Group B Streptococcus Infection in Preterm Premature Rupture of Membranes Mohamed Mohamed Gebriel, Adel Aly Elbghdady, Mohamed Elsayed Abo Ghabsha and Maged Abd Elatef Abd Elftah* \\ * Department of Obstetrics and Gynecology, Faculty of Medicine - AL-Azhar University Corresponding author: Maged Abd Elatef Abd Elftah
}

\begin{abstract}
Background: group B streptococcus (GBS) can cause significant morbidity in pregnant women. Manifestations of symptomatic maternal infection include chorioamnionitis, endometritis, cystitis, pyelonephritis and febrile GBS bacteremia. Objective: this work aimed to assess the effectiveness of penicillins versus erythromycin in treatment GBS infection following PPROM. Patients and Methods: the study included 50 pregnant females presented with PPROM before 36 weeks gestation who were attending to Outpatient Obstetrician Clinic at El Sayed-Galal University Hospital. The cases were classified into 2 groups, 25 cases each as follows: Group A (penicillin- treated group) and group B (erythromycin-treated group). Results: the results of the study showed that there were no significant difference between the cases within the two study groups as regard the different demographic data, the obstetric history and the state of the current pregnancy. There was a significant difference between the two groups as regards the fetal and maternal outcomes being less in group A (penicillin-treated group). Conclusion: our study revealed the superiority of penicillin over erythromycin in treatment of GBS associated maternal infections.
\end{abstract}

Keywords: Penicillin, Erythromycin, GBS, PPROM.

\section{INTRODUCTION}

Group B streptococcus (GBS) is a type of bacteria that is naturally found in the digestive and lower reproductive tracts of both men and women. About 1 in 4 pregnant women carry or colonized with GBS ${ }^{(\mathbf{1})}$. Streptococcus agalactiae, often referred to as GBS, is a Gram-positive bacterium that has been identified as a human pathogen since the early 1900 s $^{(2)}$. GBS can cause significant morbidity in pregnant women. Manifestations of symptomatic maternal infection include chorioamnionitis, endometritis, cystitis, pyelonephritis and febrile GBS bacteremia. Caesarean delivery appears to be a prominent risk factor for postpartum endomyometritis ${ }^{(3)}$.

Group B streptococcal genital colonization has been considered a possible cause of premature deliveries and premature rupture of membranes (PROM) although definite evidence of a causal relationship is still lacking. Several prospective studies have also suggested that GBS colonization may play a causal role in the occurrence of intrauterine deaths, late abortions and low birth weight infants ${ }^{(4)}$. Babies can be infected by GBS several months of age before birth due to their underdeveloped immune system. Only few babies who are exposed to GBS become infected, but GBS can cause miscarried, stillbirth, sepsis, meningitis and pneumonia (5). Fortunately, most GBS infection that develops at birth can be prevented if woman, who have tested positive, receives proper antibiotics (2). When membrane ruptures before 36 weeks gestation, this is known as preterm premature rupture of membrane (PPROM) ${ }^{(6)}$.

PPROMs complicates 2 to $3 \%$ of pregnancy and accounts for $40 \%$ of preterm deliveries (PPROM is associated with serious neonatal morbidity and mortality because of prematurity, infection, and prolonged oligohydramnios ${ }^{(7)}$.

Infection can either be the cause or a consequence of PPROM. It has been reported that positive amniotic fluid cultures are detected in $32.4 \%$ of patients and that 25 to $29 \%$ of patients diagnosed with PPROM developed clinical chorioamnionitis before delivery ${ }^{(\mathbf{8})}$. Chorioamnionitis itself can cause neonatal sepsis, intracranial hemorrhage, respiratory distress syndrome, and cerebral palsy ${ }^{(9)}$.

A meta-analysis has shown that using erythromycin or penicillin as empirical antibiotics following PPROM is associated with a significant reduction in chorioamnionitis, whereas co-amoxiclav is associated with increased number of necrotizing enterocolitis (NEC) ${ }^{(7)}$.

Erythromycin is therefore preferred to coamoxiclav as the first-line regime in the guidelines of some professional bodies. However, although erythromycin is a broad-spectrum antibiotic, it is less effective at treating GBS infections, which remains as the predominant pathogen in causing early onset neonatal sepsis, due to the insensitivity of the GBS bacterium in some patients ${ }^{(\mathbf{1 0})}$.

\section{AIM OF THE WORK}

This work aimed to assess the effectiveness of penicillin versus erythromycin in treatment of GBS infection following PPROM.

\section{PATIENT AND METHODS}

\section{Study design:}

This was a retrospective cohort study designed for pregnant women diagnosed with PPROM before 36 weeks of gestation and who had delivery between 24 
and 36 weeks, who were attending to Outpatient Obstetrician Clinic at Sayed Galal Hospital. The study was conducted between April 2017 and March 2018. This study aimed to determine the prevalence of GBS infection among woman presenting with PPROM and whether the treatment with penicillin or erythromycin have the same efficacy or not.

Study subject: This study included 50 cases, who were divided into:

Group A (penicillin-treated group): Included 25 cases that were given $2 \mathrm{~g}$ ampicillin intravenously as a loading dose, and followed by $250 \mathrm{mg}$ oral amoxicillin three times daily.

Group B (erythromycin-treated group): Included 25 cases that were given $250 \mathrm{mg}$ erythromycin to be given orally four times daily.

Setting: Outpatient Obstetrician Clinic at Sayed Galal Hospital, Al-Azhar University, Cairo, Egypt.

\section{Inclusion criteria:}

Female cases showed the following criteria:

1. Pregnant between $24-36$ weeks.

2. Diagnosed with PPROM

3. All gravidity

4. Age $\geq 18 \leq 38$

5. positive GBS culture

Exclusion criteria:

1. PROM $<24$ or $>36$ weeks.

2. Females in active labor

3. Any placental insufficiency or abnormality

4. Signs of chorioamnionitis eg fetal tachycardia.

5. On cervical cercelage.

Patients consent: A written informed consent was obtained from all participants before inclusion in the study, explaining the value of the study, plus the procedures that will be commenced.

Ethical consideration: The whole study design was approved by the Ethics Committee of the Department of Obstetrics and Gynecology, faculty of medicine, Al-Azhar University.

Methods: All cases in the study were subjected to the following:

(1) Complete history taking.

(2) Clinical examination:

a) General examination.

b) Abdominal examination.

c) Obstetric ultrasound (trans-abdominal).

\section{Detailed methodology:}

- Women were diagnosed to have PPROM based on clinical history and sterile speculum examination demonstrating the presence of amniotic fluid in the vagina.

- Women who were diagnosed to have PPROM before 34 weeks of gestation and who were not in active labor and showed no clinical evidence of chorioamnionitis or placental abruption were admitted for expectant management in accordance with our department protocol.

- Women were managed under this protocol as follows:
Four doses of 6-mg dexamethasone to be given intramuscularly every 12 hours. Prophylactic antibiotic to be given for 10 days or until delivery, which ever occurred earlier.

$>$ Cases were divided into two groups:

- Group A (penicillin-treated group)

Included 25 cases that were given $2 \mathrm{~g}$ ampicillin intravenously as a loading dose, and followed by $250 \mathrm{mg}$ oral amoxicillin three times daily.

- Group B (erythromycin-treated group)

Included 25 cases that were given $250 \mathrm{mg}$ erythromycin to be given orally four times daily.

- A high vaginal swab and midstream urine sample to be taken for bacterial culture and subsequent treatment was given according to the culture result.

- The patients were hospitalized for observation for any clinical sign or symptom of chorioamnionitis. If chorioamnionitis is suspected, prompt delivery was advised.

$>$ Vaginal swab technique:

The lady was asked to be in lithotomy position and with sterile gloves a sterile speculum was inserted in the vagina and a high vaginal swab was taken by a cotton swab in polypropylene tube with polystyrene stick and sent for culture and sensitivity. Statistical analysis of data:

The collected data were coded, processed and analyzed using the SPSS (Statistical Package for Social Sciences) version 22 for Windows ${ }^{\circledR}$ (SPSS Inc, Chicago, IL, USA). Data of categorical variables were presented as number (frequency) and comparison between two groups containing qualitative data was compared using Chi-Square test $(\chi 2)$. Quantitative data was checked for normal distribution by using Kolmogorov-Smirnov test. Parametric data was presented as mean $\pm \mathrm{SD}$. Student t-test was used to compare two groups with parametric quantitative data (expressed as $\mathrm{t}$ ). Non parametric data was presented as median (min - max). Mann-Whitney test (expressed as z) was used for comparison between groups. The correlation between continuous normally distributed data was performed by Pearson's correlation while Spearman's correlation was used to test the correlation between continuous not normally distributed data (expressed as r).

Level of significance:

For all the above mentioned tests, the level of significance was tested, expressed as the probability of (p-value) and the results was explained as following:

- Non-significant if the $\mathrm{p}$ value is $>0.05$

- Significant if the $\mathrm{p}$ value is $\leq 0.05$.

- Highly significant if the $p$ value $<0.001$

\section{RESULTS}

Cases selection:

There were 3, 138 women who had a singleton pregnancy and delivered in our unit between April 2017 and October 2018. Among these deliveries, 350 
(1.8\%) deliveries were from women who were confirmed to have PPROM. 85 women (13\%) who were found to have a positive GBS culture results after admission (active carrier). 35 females were not included in our study due to different causes and the remaining 50 females were the cases included in our study.

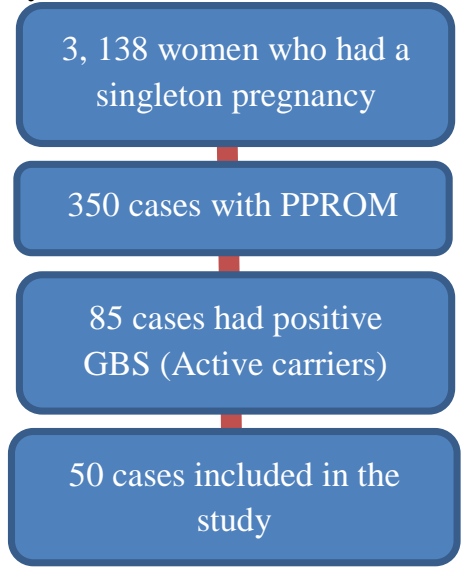

Figure (1): Flow chart of the process of case selection

- The 50 cases within the study had been classified into two groups according to the treatment regimen, Group A (penicillin-treated group) and Group B (erythromycin-treated group).

- The demographic data of the cases within the two study groups are illustrated in table (1).

- The mean age of the cases in group A was $25.34 \pm 3.17$ years and was $24.17 \pm 2.94$ years in group B with no statistically significant difference between the two groups $(\mathrm{p}=0.759)$.

- The mean body weight of the cases in group A was $79.16 \pm 9.15 \mathrm{~kg}$ and was $74.45 \pm 10.92 \mathrm{~kg}$ in group B with no statistically significant difference between the two groups $(\mathrm{p}=0.162)$.

- The mean BMI of the cases in group A was $22.7 \pm$ 1.8 and was $22.8 \pm 1.9$ in group B with no statistically significant difference between the two groups $(\mathrm{p}=$ 0.894).

Table (1): Demographic data of the cases within the study groups

\begin{tabular}{|c|c|c|c|}
\hline Items & $\begin{array}{l}\text { Group A } \\
\text { (penicillin } \\
\text { treated group) } \\
\mathbf{N}=\mathbf{2 5}\end{array}$ & $\begin{array}{c}\text { Group B } \\
\text { (erythromycin } \\
\text { treated group) } \\
\mathbf{N}=\mathbf{2 5}\end{array}$ & $\begin{array}{l}\text { Test of } \\
\text { significance }\end{array}$ \\
\hline $\begin{array}{l}\text { Age } \\
\text { (years) }\end{array}$ & $25.34 \pm 3.17$ & $24.17 \pm 2.94$ & $\begin{array}{l}\mathrm{t}=0.864 \\
\mathrm{P}=0.759\end{array}$ \\
\hline $\begin{array}{l}\text { Weight } \\
\text { (kg) }\end{array}$ & $79.16 \pm 9.15$ & $74.45 \pm 10.92$ & $\begin{array}{l}\mathrm{t}=1.963 \\
\mathrm{P}=0.162\end{array}$ \\
\hline BMI & $22.7 \quad \pm 1.8$ & $22.8 \quad \pm 1.9$ & $\begin{array}{l}\mathrm{t}=-0.616 \\
\mathrm{P}=0.894\end{array}$ \\
\hline
\end{tabular}

P: probability. t: independent samples t-test.

Continuous data expressed as mean $\pm \mathrm{SD}$.
Table (2) showed that only 3 cases in group A (12\%) were primigravida and 4 cases in group B (16\%) were primigravida. From the cases of multigravida in group A, 4 cases were nullipara (16\%) while 18 cases had given birth to children before (72\%).

In group B, 6 cases were nullipara (24\%) while 15 cases had given birth to children before $(60 \%)$ with no significant difference in the history of gravidity or parity between the cases of the two groups ( $\mathrm{p}=0.634$ and 0.105 respectively). 11 cases $(44 \%)$ had previous normal vaginal delivery and 7 cases (28\%) had CS in group A.

While in group B, 10 cases (40\%) had previous normal vaginal delivery and 4 cases $(16 \%)$ had CS with no significant difference between the two groups $(p=0.094)$. Only 4 cases $(16 \%)$ had history of previous abortion and $3(12 \%)$ cases had previous history of GBS during previous pregnancies in group A.

While in group B, 6 cases (24\%) have history of previous abortion and $5(20 \%)$ cases had previous history of GBS during previous pregnancies.

Table (2): Analysis of the obstetric history of the cases within the two groups

\begin{tabular}{|c|c|c|c|}
\hline Items & $\begin{array}{c}\text { Group A } \\
\text { (penicillin } \\
\text { treated } \\
\text { group) } \\
\mathrm{N}=25\end{array}$ & $\begin{array}{c}\text { Group B } \\
\text { (erythromy } \\
\text { cin treated } \\
\text { group)- } \\
\mathrm{N}=\mathbf{2 5}\end{array}$ & $\begin{array}{c}\text { Test of } \\
\text { significance }\end{array}$ \\
\hline \multicolumn{4}{|l|}{ Gravity } \\
\hline Primigravida & $3(12 \%)$ & $4(16 \%)$ & \multirow{2}{*}{$\begin{aligned} \chi 2 & =1.067 \\
P & =0.634\end{aligned}$} \\
\hline Multigravida & $22(88 \%)$ & $21(84 \%)$ & \\
\hline \multicolumn{4}{|l|}{ Parity } \\
\hline Nulliparity & $4(16 \%)$ & $6(24 \%)$ & \multirow{2}{*}{$\begin{array}{l}\chi 2=2.349 \\
P=0.105\end{array}$} \\
\hline Multipara & $18(72 \%)$ & $15(60 \%)$ & \\
\hline \multicolumn{4}{|c|}{ Previous modes of delivery } \\
\hline $\begin{array}{c}\text { Previous } \\
\text { NVD }\end{array}$ & $11(44 \%)$ & $10(40 \%)$ & \multirow[t]{2}{*}{$\begin{array}{c}\chi 2=2.734 \\
P=0.094\end{array}$} \\
\hline $\begin{array}{l}\text { Previous } \\
\text { CS }\end{array}$ & $7(28 \%)$ & $4(16 \%)$ & \\
\hline $\begin{array}{c}\text { Previous } \\
\text { abortions }\end{array}$ & $4(16 \%)$ & $6(24 \%)$ & $\begin{array}{c}\chi 2=1.984 \\
P=0.265\end{array}$ \\
\hline $\begin{array}{l}\text { Previous } \\
\text { GBS }\end{array}$ & $3(12 \%)$ & $5(20 \%)$ & $\begin{array}{c}\chi 2=2.007 \\
P=0.217\end{array}$ \\
\hline
\end{tabular}

P: probability. $\chi 2$ : chi-square test. Categorical data expressed as Number (\%).

The mean GA for rupture of membranes in group A was $32.49 \pm 2.63$ weeks while in group B it was $31.71 \pm 2.85$ weeks with no significant difference between the two groups ( $\mathrm{p}=0.176$ ). The mean GA for delivery in group A was $35.87 \pm 1.74$ weeks while in group B it was $35.16 \pm 1.67$ weeks with no significant difference between the two groups $(\mathrm{p}=0.763)$. 
In group A, 5 cases were known to have active GBS before rupture of membranes while the remaining 20 cases in the group were diagnosed after rupture of membranes. In group B, 12 cases were known to be active GBS carrier before rupture of membranes while the remaining 13 cases in the group were diagnosed after rupture of membranes with statistically significant difference between the two groups $(\mathrm{p}=$ 0.016). The median sepsis score in group A was 0.04 while in group B it was 0.05 with no significant difference between the two groups (0.461). These data are illustrated in table (3).

Table (3): Analysis of the current state of infection

\begin{tabular}{|c|c|c|c|}
\hline \multirow{3}{*}{ Items } & Group A & Group B & \multirow{3}{*}{$\begin{array}{c}\text { Test of } \\
\text { significance }\end{array}$} \\
\hline & $\begin{array}{l}\text { (penicillin } \\
\text { treated } \\
\text { group) }\end{array}$ & $\begin{array}{l}\text { (erythromycin } \\
\text { treated group) }\end{array}$ & \\
\hline & $\mathrm{N}=25$ & $\mathrm{~N}=25$ & \\
\hline $\begin{array}{l}\mathrm{GA} \text { at } \\
\text { rupture of } \\
\text { membranes }\end{array}$ & \multirow[t]{2}{*}{$\begin{array}{c}32.49 \pm \\
2.63\end{array}$} & \multirow[t]{2}{*}{$31.71 \pm 2.85$} & $t=1.534$ \\
\hline (weeks) & & & $\mathrm{P}=0.176$ \\
\hline \multirow{2}{*}{$\begin{array}{c}\text { GA at } \\
\text { delivery } \\
\text { (weeks) }\end{array}$} & \multirow{2}{*}{$\begin{array}{l}35.87 \pm \\
1.74\end{array}$} & \multirow{2}{*}{$35.16 \pm 1.67$} & $t=0.978$ \\
\hline & & & $\mathrm{P}=0.763$ \\
\hline \multicolumn{4}{|c|}{ GBS status } \\
\hline $\begin{array}{l}\text { Known } \\
\text { before } \\
\text { ROM }\end{array}$ & $5(20 \%)$ & $12(48 \%)$ & $\chi^{2}=4.752$ \\
\hline $\begin{array}{c}\text { Known } \\
\text { After ROM } \\
\text { and before } \\
\text { delivery }\end{array}$ & $20(80 \%)$ & $13(52 \%)$ & $\mathrm{P}=0.016^{*}$ \\
\hline \multirow{2}{*}{$\begin{array}{l}\text { Sepsis } \\
\text { score }\end{array}$} & 0.04 & 0.05 & $\mathrm{z}=-1.218$ \\
\hline & $\begin{array}{c}(0.03- \\
0.11)\end{array}$ & $(0.02-0.10)$ & $\mathrm{P}=0.461$ \\
\hline
\end{tabular}

P: probability. $\chi 2$ : chi-square test.

t: independent samples t-test z: Mann-Whitney test.

Categorical data expressed as number (\%). Continuous data expressed as mean $\pm \mathrm{SD}$. Or (median or range).

As regards the different outcomes within the two study groups, the data are illustrated in table (4). No cases were positive for GBS at the second swab in group A, while 5 cases remained positive $(20 \%)$ in group $\mathrm{B}$ with statistically significant difference between the two groups $(\mathrm{p}=0031)$.

The median sepsis score in group A was highly statistically lower than the score in group B (p < $0.001)$. The children of 2 cases ( $8 \%$ ) were admitted to NICU in group A and the children of 9 cases (36\%) were admitted to NICU in group B with high level of significance between the two groups $(\mathrm{p}<0.001)$.
Table (4): Comparison of the outcomes of the two groups

\begin{tabular}{|c|c|c|c|}
\hline \multirow[t]{2}{*}{ Items } & $\begin{array}{c}\text { Group A } \\
\text { (penicillin } \\
\text { treated } \\
\text { group) } \\
\end{array}$ & $\begin{array}{c}\text { Group B } \\
\text { (erythromycin } \\
\text { treated } \\
\text { group) }\end{array}$ & \multirow[t]{2}{*}{$\begin{array}{c}\text { Test of } \\
\text { significance }\end{array}$} \\
\hline & $N=25$ & $\mathrm{~N}=25$ & \\
\hline \multicolumn{4}{|c|}{ GBS status at the second swab (after treatment) } \\
\hline Positive & $0(0 \%)$ & $5(20 \%)$ & $\chi 2=7.832$ \\
\hline negative & $25(100 \%)$ & $20(80 \%)$ & $\mathrm{P}=0.001 *$ \\
\hline \multirow[b]{2}{*}{$\begin{array}{l}\text { Sepsis } \\
\text { score }\end{array}$} & 0 & 0.03 & $z=-4.583$ \\
\hline & $(0-0.04)$ & $(0.01-0.08)$ & $\begin{array}{c}\mathrm{P}=< \\
0.001 * *\end{array}$ \\
\hline \multirow{2}{*}{ CS } & \multirow{2}{*}{$14(28 \%)$} & \multirow{2}{*}{$17(52 \%)$} & $\chi 2=2.632$ \\
\hline & & & $\mathrm{P}=0.128$ \\
\hline \multirow{2}{*}{$\begin{array}{c}\text { Birth } \\
\text { weight } \\
(\mathrm{kg})\end{array}$} & \multirow[b]{2}{*}{$3.2 \pm 0.4$} & \multirow[b]{2}{*}{$3.1 \pm 0.4$} & $\mathrm{t}=1.942$ \\
\hline & & & $\mathrm{P}=0.185$ \\
\hline $\begin{array}{c}\text { Neonatal } \\
\text { ICU }\end{array}$ & $2(8 \%)$ & $9(36 \%)$ & $\begin{array}{c}\chi^{2}=8.573 \\
\mathrm{P}=<0.001^{* *}\end{array}$ \\
\hline
\end{tabular}

P: probability. $\chi 2$ : chi-square test.

t: independent samples t-test z: Mann-Whitney test.

Categorical data expressed as number (\%).

Continuous data expressed as mean $\pm \mathrm{SD}$. Or (median or range).

\section{DISCUSSION}

In 1981, Regan et al. ${ }^{(11)}$ demonstrated that PROM to be more common among gravidas with positive cervical GBS cultures at the time of delivery. Moller et al. ${ }^{(12)}$ found increases in both PPROM and preterm labor with GBS carriage. Matorras et al. ${ }^{(13)}$ also identified PPROM to be more common in GBS carriers than non-carriers. Bobitt et al. ${ }^{(14)}$ found PPROM leading to delivery of low-birth-weight infants to be more common in women carrying GBS remote from delivery. Katz ${ }^{(\mathbf{1 5})}$ demonstrated that there was an increased incidence of PROM $(\mathrm{P}<0.01)$ and preterm labor $(\mathrm{P}<0.001)$ among GBS carriers, and suggested a relationship between gestational age at positive culture and subsequent adverse outcome. In a retrospective analysis, Alger et al. ${ }^{(16)}$ found PROM to be more frequent among GBS carriers.

On the contrary, Zhang et al. ${ }^{(17)}$ evaluated obstetric outcomes in GBS carriers and found an increased risk of prematurity and low birth weight but no association with PROM.

The incidence of PPROM of membranes in our study was $11.15 \%$. This comes in agreement with the results reported by Yeung et al. (18), which is comparable to the rate reported in the literature.

Among total number of 350 cases with PPROM who attended to our hospital, 85 cases were found to have active GBS infection. From this number, 50 cases were included in our study. The prevalence of GBS 
infection in cases with GBS included in our study was about $24.84 \%$. This prevalence is similar to the worldwide prevalence that was reported to range from $10-30 \%$ of pregnant women. Natarajan et al. ${ }^{(19)}$ reported that GBS colonization in a study of pregnant women in Hong Kong was $14.6 \%$. Waters et al. ${ }^{(20)}$ and Yudin et al. ${ }^{(21)}$ reported that the prevalence of GBS among pregnant women included in their studies were $20.3 \%$ and $21 \%$ respectively, values that are just near what reported in our study. This reported variations could be attributed to many reasons including the use of different culture methods and culture from different anatomic sites. Geographic variations are associated with the lower incidence where the neonatal GBS rates are known to be low.

Rapid testing for GBS made confirmation or exclusion of the GBS carrier status. More and more rapid tests for GBS have been developed, including polymerase chain reaction, optical immunoassay, DNA hybridization, enzyme immunoassay, and latex agglutination ${ }^{(22)}$.The rapid tests can overcome the problem of slow reporting time of the traditional bacterial culture, thereby allowing obstetricians to give appropriate antibiotic treatment accordingly. This could prevent the risk of over treating mothers with broad-spectrum antibiotics. However, the rapid tests are costly and not readily available in our clinical setting. Before the rapid tests become readily available, it is practically difficult to identify the active carriers before delivery, and ampicillin/amoxicillin appeared to be a better prophylactic antibiotic for women presenting with PPROM to prevent neonatal GBS infection if the GBS carriage status is unknown (23).

In our study, The mean GA for rupture of membranes in group A was $32.49 \pm 2.63$ weeks while in group $\mathrm{B}$ it was $31.71 \pm 2.85$ weeks with no significant difference between the two groups $(\mathrm{p}=$ 0.176 ). The mean GA for delivery in group A was $35.87 \pm 1.74$ weeks while in group B it was $35.16 \pm$ 1.67 weeks with no significant difference between the two groups $(p=0.763)$. These results are opposite to the results reported by Yeung et al. ${ }^{(18)}$ who reported that the mean GA for rupture of membranes in the group treated by penicillin was $32.2 \pm 3.8$ and the mean GA at delivery was $34.2 \pm 4.3$

In our results, the cases with previous history of GBS infection were 8 cases or $16 \%$ of the whole study population. This is consistent with the findings of Phares et al. ${ }^{(24)}$ where the cases included in this study revealed high risk of recurrence with previous history of GBS. Cheng and his colleagues ${ }^{(9)}$ documented that the rate of recurrence of GBS colonization in the pregnancy subsequent to the index pregnancy was $38.2 \%$.

With the follow up swab in our study, no cases showed resistance to penicillin while 5 cases were resistant to erythromycin (20\%) with statistically significant difference between the two groups $(\mathrm{p}=0.001)$. Our results also confirmed the results reported by Yeung et al. ${ }^{(18)}$ who found that penicillin are superior to erythromycin in preventing neonatal GBS infection in mothers who were active GBS carriers. This result was likely related to the high erythromycin resistant rate in our locality. In the United States, Panda et al. ${ }^{(10)}$ also observed an increase in erythromycin resistance $(25.5 \%)$ in their institution. However, there was no analysis with regard to the effect of any particular antibiotic in preventing neonatal GBS infection in women with PPROM. It has been found that when penicillin, ampicillin, or cefazolin prophylaxis was administered for more than 4 hours before delivery to GBScolonized women delivering before 37 weeks, antibiotic prophylaxis was $78 \%$ effective in preventing early onset GBS disease. No data were available on the effectiveness of antibiotics given before the intrapartum period in GBS-colonized women with PPROM for preventing neonatal GBS sepsis ${ }^{(2)}$.

This came in contrast with the results of a previous small randomized controlled trial involving the use of antepartum ampicillin in patients with PPROM, which found no difference in the incidence of neonatal NEC between the treatment group $(0 \%, \mathrm{~N}$ $1 / 48)$ and the placebo group $\left(14 \%, \mathrm{~N}^{1 / 4} 7\right)^{(25)}$.

In our results, there were significant differences in the sepsis score between the mothers in the two groups after treatment. This came in the contrast with the results reported by Park et al. ${ }^{(26)}$ and Poliquin $\boldsymbol{e t}$ al. ${ }^{(27)}$ who revealed no significant difference in the sepsis score between the different types of antibiotic used. On the contrast, our results showed no significant difference between the antibiotics used and the rate of CS or the birth weight of the neonates. This agreed with results of other two studies who documented no difference in the delivery or the neonatal outcomes according to the type of the antibiotic used ${ }^{(26,27) .}$

In conclusion, our study revealed the superiority of penicillin over erythromycin in treatment of GBS associated maternal infections.

\section{CONCLUSIONS}

\section{From this study, it could be concluded that:}

1. Group B streptococcus (GBS) is a major cause of neonatal and maternal complication.

2. The rate of complications increased in cases of PPROM.

3. Proper antibiotic treatment reduces the incidence of both neonatal and fetal complications.

4. Penicillin was associated with better protective effect than erythromycin in decreasing the incidence of complications caused by GBS in cases with PPROM. 


\section{RECOMMENDATIONS}

1. Strict follow up in females during the whole period of pregnancy especially in those with history of complications during the previous pregnancies.

2. Use of proper antibiotics to treat cases with positive GBS for prevention of complications in both mother and infant.

3. Further studies with larger number of cases are needed to help to detect the most effective antibiotics in prevention of GBS related complications with the proper regimen of application.

\section{REFERENCES}

1. Roesch LFW, Silveira RC, Corso AL et al. (2017): Diversity and composition of vaginal microbiota of pregnant women at risk for transmitting Group B Streptococcus treated with intrapartum penicillin. PLoS One, 12 (2): 169-173.

2. Verani JR, McGee L, Schrag SJ (2010): Prevention of perinatal group B streptococcal disease." Morbidity and Mortality Weekly Report (MMWR), Revised Guidelines from CDC. Recommendations and Reports, 59 (10): 1-32.

3. Tsoi E, Fuchs I, Henrich W et al. (2004): Sonographic measurement of cervical length in preterm prelabor amniorrhexis. Ultrasound in Obstetrics and Gynecology, 24 (5): 550-553.

4. Myles TD, Elam G, Park-Hwang E et al. (1998): The Jarisch-Herxheimer reaction and fetal monitoring changes in pregnant women treated for syphilis. Obstetrics \& Gynecology, 92 (5): 859-864.

5. Batz MB, Henke E, Kowalcyk B (2013): Long-term consequences of foodborne infections. Infectious Disease Clinics, 27 (3): 599-616.

6. Poutakidis G (2016): Treatment of bacterial vaginosis in early pregnancy and its effect on spontaneous preterm delivery and preterm rupture of membranes. Clinical Microbiology, 5 (5): 36-39.

7. Kenyon S, Taylor D, Tarnow-Mordi W (2001): Broadspectrum antibiotics for preterm, prelabour rupture of fetal membranes: the ORACLE I rand omised trial. The Lancet, 357 (9261): 979-988.

8. Romero R, Gómez R, Chaiworapongsa T et al. (2001): The role of infection in preterm labour and delivery. Paediatric and perinatal epidemiology, 15: 41-56.

9. Aziz N, Cheng YW, Caughey AB (2009): Neonatal outcomes in the setting of preterm premature rupture of membranes complicated by chorioamnionitis. The Journal of Maternal-Fetal \& Neonatal Medicine, 22 (9): 780-784.

10.Panda B, Iruretagoyena I, Stiller $R$ et al. (2009): Antibiotic resistance and penicillin tolerance in ano-vaginal group B streptococci. J Matern Fetal Neonatal Med., 22: 111-114.

11. Regan JA, Chao S, James L (1981): Premature rupture of membranes, preterm delivery, and group B streptococcal colonization of mothers. American Journal of Obstetrics and Gynecology, 141 (2): 184-186.

12. Moller M, Borch K, Thomsen A et al. (1984): Rupture of fetal membranes and premature delivery associated with group B streptococci in urine of pregnant women. The Lancet, 324 (8394): 69-70.
13. Matorras $R$, Garcia-Perea $A$, Madero $R$ et al. (1991): Maternal colonization by group $\mathrm{B}$ streptococci and puerperal infection, analysis of intrapartum chemoprophylaxis. European Journal of Obstetrics, 38 (3): 203-207.

14.Bobitt JR, Ledger WJ (1976): Obstetric observations in eleven cases of neonatal sepsis due to the group B beta hemolytic streptococcus. Obstetrics and Gynecology, 47 (4): 439-442.

15. Katz VL (1993): Management of group B streptococcal disease in pregnancy. Clinical Obstetrics and Gynecology, 36 (4): 832-842.

16. Alger LS, Lovchik JC, Hebel JR et al. (1988): The association of Chlamydia trachomatis, Neisseria gonorrhoeae, and group B streptococci with preterm rupture of the membranes and pregnancy outcome. American Journal of Obstetrics and Gynecology, 159 (2): 397-404.

17.Zhang J, Yuan L, Yang Y (1995): Perinatal colonization of group B Streptococcus: a study in 600 cases in Beijing Tiantan Hospital. Zhonghua liuxingbingxue zazhi, 16 (1): 36-39.

18. Yeung SW, Sahota DS, Leung TY (2014): Comparison of the effect of penicillins versus erythromycin in preventing neonatal group B streptococcus infection in active carriers following preterm prelabor rupture of membranes. Taiwanese Journal of Obstetrics and Gynecology, 53 (2): 210-214.

19. Natarajan G, Johnson YR, Zhang F et al. (2006): Realtime polymerase chain reaction for the rapid detection of group B streptococcal colonization in neonates. Pediatrics, 118 (1): 14-22.

20. Waters TP, Mercer B (2011): Preterm PROM: prediction, prevention, principles. Clinical Obstetrics and Gynecology, 54 (2): 307-312.

21. Yudin MH, van Schalkwyk J, Van Eyk et al. (2009): Antibiotic therapy in preterm premature rupture of the membranes. Journal of Obstetrics and Gynaecology Canada, 31 (9): 863-867.

22.Honest H, Sharma S, Khan KS (2006): Rapid tests for group B Streptococcus colonization in laboring women: a systematic review. Pediatrics, 117 (4): 1055-1066.

23.Di Renzo GC, Melin P, Berardi A et al. (2015): Intrapartum GBS screening and antibiotic prophylaxis: a European consensus conference. The Journal of MaternalFetal \& Neonatal Medicine, 28 (7): 766-782.

24.Phares CR, Lynfield R, Farley MM et al. (2008): Epidemiology of invasive group B streptococcal disease in the United States, 1999-2005. Jama., 299 (17): 2056-2065.

25. Grable IA, Garcia PM, Perry D et al. (1996): Group B Streptococcus and preterm premature rupture of membranes: a rand omized, double-blind clinical trial of antepartum ampicillin. American Journal of Obstetrics and Gynecology, 175 (4): 1036-1042.

26.Park SE, Jiang S, Wessels MR (2012): CsrRS and environmental $\mathrm{pH}$ regulate group $\mathrm{B}$ streptococcus adherence to human epithelial cells and extracellular matrix. Infection and Immunity, 11: 612-616.

Poliquin V, Albert A, Castillo E et al. (2016): 39: Prognosis after preterm premature rupture of membranes (PPROM) for women with history of genital and nongenital infections. American Journal of Obstetrics \& Gynecology, 215 (6): 845-852. 